\title{
Soil-water interaction affecting a deep-seated landslide: From field monitoring to experimental analysis
}

\author{
Xuan Kang ${ }^{1,2} \cdot$ Shun Wang ${ }^{2,4} \cdot$ Wei Wu$^{2} \cdot$ Guangli Xu${ }^{1} \cdot$ Jinqian Zhao ${ }^{3} \cdot$ Fusheng Liu ${ }^{3}$
}

Received: 16 April 2021 / Accepted: 20 October 2021 / Published online: 31 January 2022

(c) The Author(s) 2022, corrected publication 2022

\begin{abstract}
Most deep-seated landslides are characterized by large volumes with deep shear surfaces. They are sensitive to hydrological forcing, especially in climate change scenarios. This paper studies the role of soil-water interaction in affecting the motion of a deep-seated landslide near the southeast coast of China, where seasonal rainfall combined with annual typhoons caused the instability of a previous stable slope. A comprehensive investigation consisting of field monitoring and experiments of soil-water interaction is carried out. The monitoring data show that the landslide exhibits alternate dormant and active stages, corresponding to rainy and dry seasons, respectively. The enduring precipitations predominate the landslide motion, while intensive rainfall brought by typhoon events leads to transient deformation. In addition, wet treatment of intact and reconstituted soils is adopted to mimic the interaction between rainwater and landslide material. The results obtained from in-situ and laboratory direct shear tests indicate that the soil-water interaction is time-dependent. The long-term interaction gives rise to significant strength reduction of soils, thereby regulating the movement of the landslide.
\end{abstract}

Keywords Deep-seated landslide $\cdot$ Field monitoring $\cdot$ Hydrological conditions $\cdot$ In-situ test $\cdot$ Soil-water interaction

\section{Introduction}

Deep-seated landslides occur all around the world and are known for their huge sliding mass with deep-buried shear surfaces. Especially in mountainous areas, they could be initiated by self-weight, earthquake, and hydrological forcing (Ronchetti et al. 2010; Scaringi et al. 2018a; Wang et al. 2021), posing serious threats to settlements and infrastructures, such as railways, reservoirs, and telecommunication lines. Many studies revealed that the movement of

Wei Wu

wei.wu@boku.ac.at

1 Engineering Faculty, China University of Geosciences, Wuhan 430074, PR China

2 Institute of Geotechnical Engineering, University of Natural Resources and Life Sciences, Feistmantelstrasse 4, Vienna A-1180, Austria

3 China Railway Siyuan Survey and Design Group., LTD., Wuhan 430063, PR China

4 State Key Laboratory of Water Resources and Hydropower Engineering Science, Institute of Engineering Risk and Disaster Prevention, Wuhan University, 299 Bayi Road, Wuhan 430072, PR China deep-seated landslides is time-dependent and sensitive to hydrological conditions. They usually show accelerated or delayed response to external forcing, e.g., rainfall, snowmelt, and fluctuations of reservoir water level (Zanger et al. 2010; Agliardi et al. 2020). Currently, our understanding of the interplay between landslide motion and hydrological conditions and the interactions behind these processes is mainly based on statistic analysis of in-situ observations. In this regard, long-term and multi-parameter monitoring systems are widely utilized as the fundamental approach during the early warning process of deep-seated landslides (Corominas et al. 2014; Bossi et al. 2017). Nevertheless, due to the time-varying hydrological condition in deep-seated landslides, quantifying the landslide development still remains a major challenge.

Usually, rainfall is the most important type of hydrological forcing. Its effects on landslide movement have been the subject of many previous studies (Wang and Sassa 2003; Crosta and Frattini 2008; Wang et al. 2021a; Wang and Idinger 2021b). For deep-seated landslides, rainfall may temporarily accelerates the slope movement (Wang et al. 2018). In some coastal areas, typhoon events usually bring intensive rainfalls, which may lead to various mass 
movements. For instance, Typhoon Morakot in August 2009 caused numerous landslides in its striking region, resulting in severe destructions and casualties (Tsou et al. 2011). Likewise, Typhoon Talas had a major contribution in the occurrences of more than 70 deep-seated landslides in the Japanese Islands in 2011 (Hirata and Chigira 2019). However, most researches focus on the transient effect during intensive precipitation. From a long-term perspective, typhoon-triggered rainfall also causes intensive interaction between landslide materials and water, leaving considerable uncertainties on the risk of the involved landslides. Therefore, it is necessary to investigate the effects of rainfall in regulating the motion of deep-seated landslides.

Many deep-seated landslides are characterized by preexisting shear zones, which are clay-rich layers dividing the underlying bedrock and the overlying sliding masses. For these landslides, the majority of displacement may localize in the shear zone, where the pore water plays an important role in changing the behaviour of the soil (Scaringi 2016; Wang et al. 2021c). Many studies show that the shear zones of deep-seated landslides are particularly sensitive to hydrological perturbations (Petley and Allison 1997; Madritsch and Millen 2007). The existence of pore water can alter the stress state within the shear zones, resulting in sudden or delayed feedback in landslide movement (Dawson et al. 1999; Stark et al. 2005). For decades, researchers have gathered monitoring data to better understand the correlations between landslide motion and various internal and external factors. Nevertheless, geological materials and hydrological conditions of landslides are subjected to change with time. Hence, the failure mechanisms can be better appreciated by carrying out field and laboratory tests on soil samples from the shear zone.

This work reports the correlation between rainfall and the motion of a deep-seated landslide located near the southeast coastal area of China. This region is severely affected by the annual typhoon events originated from the Pacific Ocean. We look into the possible triggering factors of this landslide with the help of a multi-pronged approach, including field monitoring observation, underground tunnelling exploration, in-situ and laboratory experiments. The experiments pay particular attention to the role of soil-water interaction in regulating the movement of the landslide.

\section{Generalities of Xiageliao landslide}

\section{Geological setting}

The Xiageliao landslide under study is located near the southeast coast of Zhejiang Province, China (11959"14"N, $28^{\circ} 20^{\prime} 36^{\prime \prime E}$ ) (see Fig. 1). This area features a monsoon season, rainfall, humidity, and typhoons. The annual average rainfall is between $850 \mathrm{~mm}$ to $1950 \mathrm{~mm}$. Every hydrologic year, nearly $80 \%$ of precipitation concentrates in the wet season from March to September. During this time, several typhoons make landfall in this region and bring torrential rain with gale, inducing instabilities of deep-seated landslides.

Located on the east bank of the Daxi River, the Xiageliao landslide is approximately $15 \mathrm{~km}$ south of Lishui city. Fig. 2 shows that this landslide is roughly symmetrical triangularshaped, broadening in the sliding direction. According to
Fig. 1 (a) The study area: Lishui city, China (b) location of the Xiageliao landslide (c) overview of the Xiageliao landslide (from Google Earth, 2016)
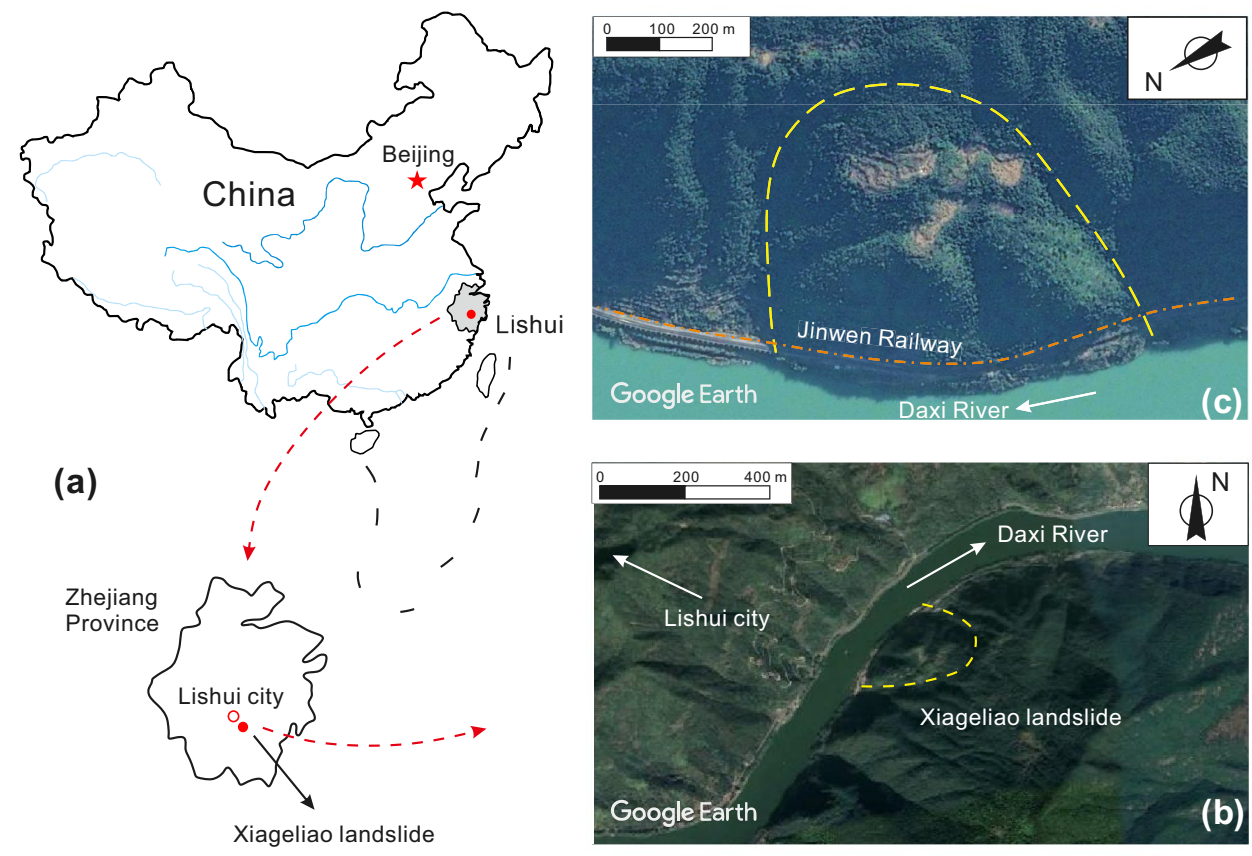


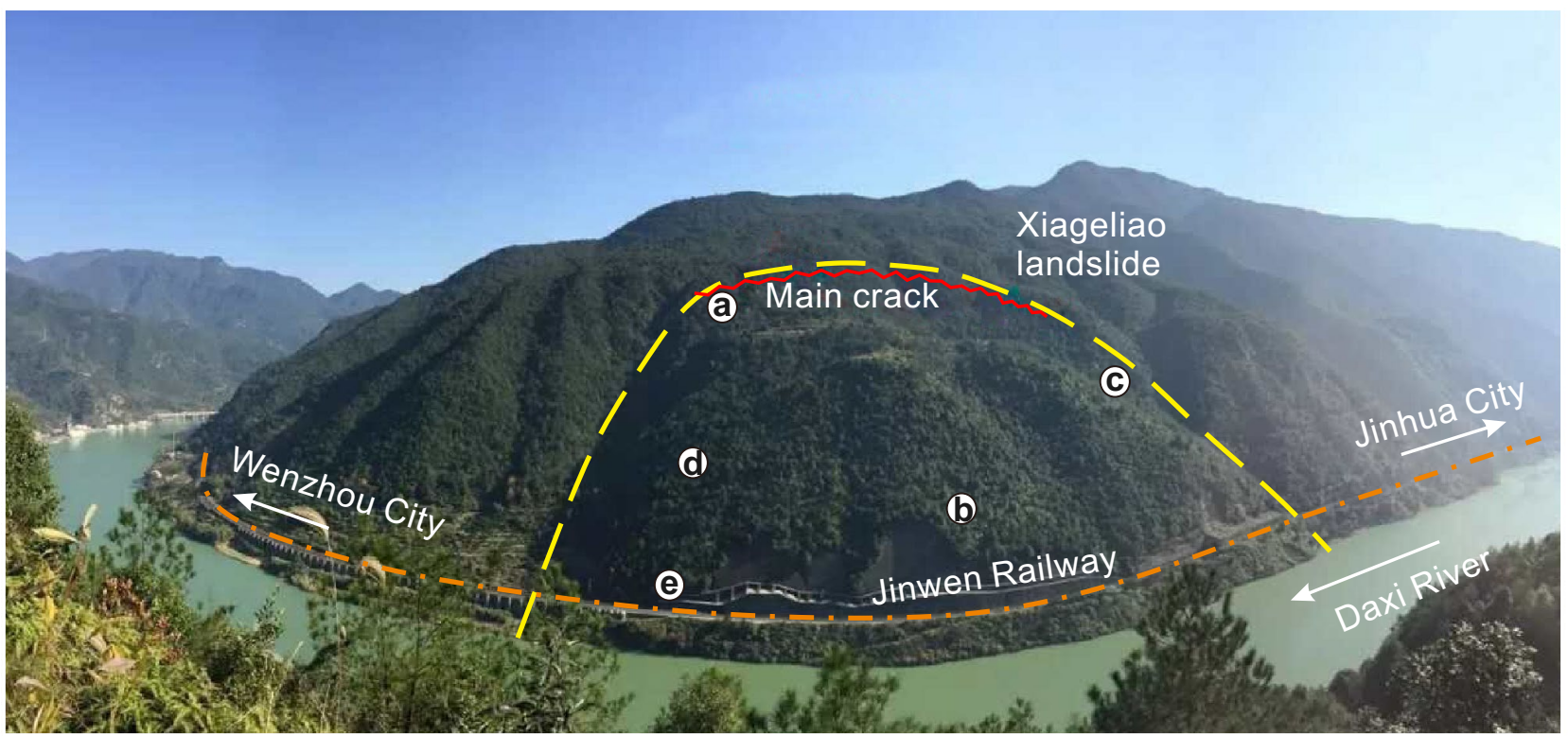

Fig. 2 Photograph of the Xiageliao landslide. The enclosed Alphanumerics (a) to (e) denote the locations with significant deformation (see Fig. 4)

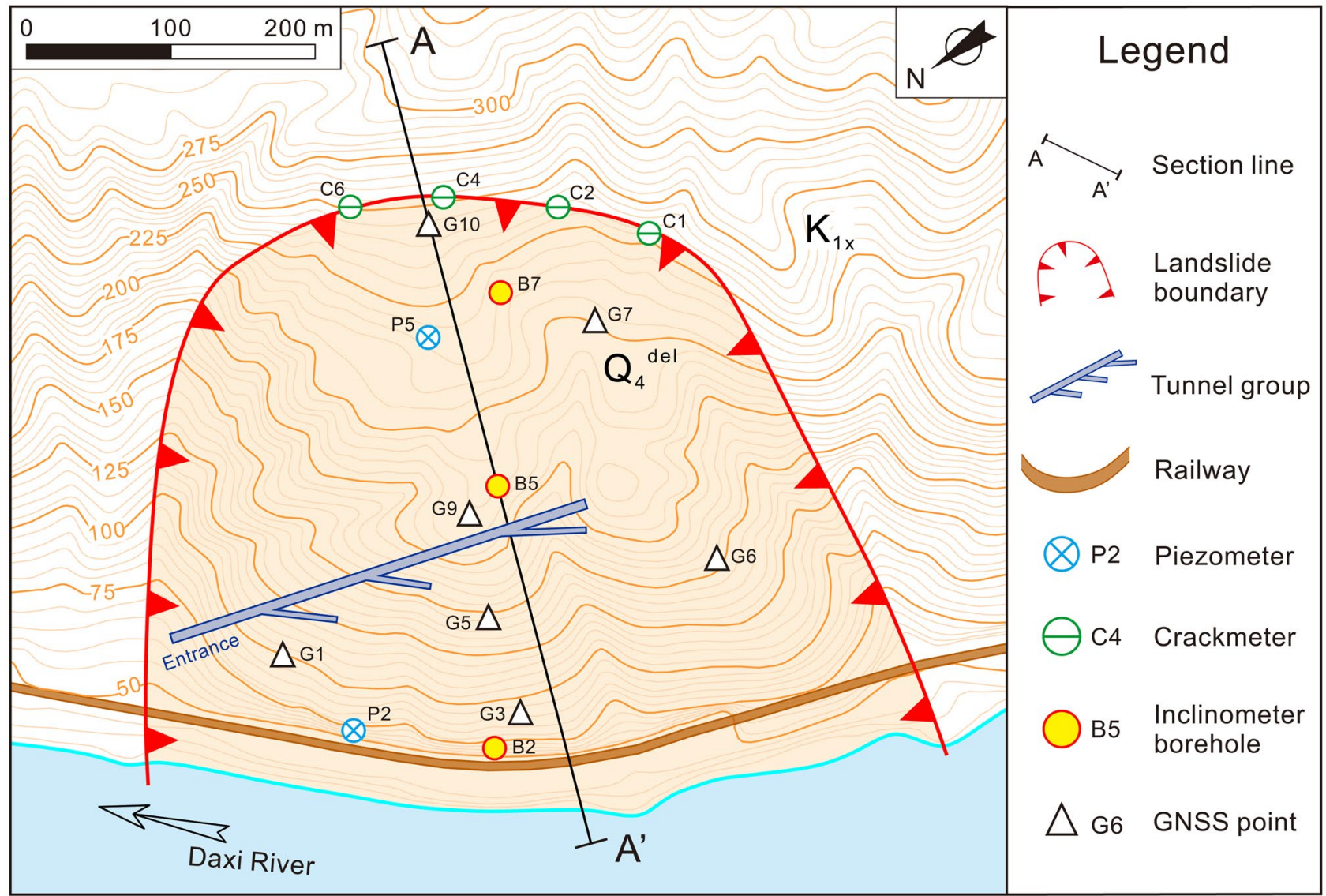

Fig. 3 Plan view of the landslide with monitoring network. The piezometers, crackmeters, inclinometers, and GNSS (Global Navigation Satellite System) points are installed to monitor the underground water level, main crack development, subsurface deformation, and superficial displacement of the landslide, respectively 
the field survey in 2016, the landslide covers a total area of $20 \times 10^{4} \mathrm{~m}^{2}$, with a volume of approximately $1.1 \times 10^{7} \mathrm{~m}^{3}$. As shown in the plan view (Fig. 3), from the toe to the main crown, the elevation increases from 35 to 265 m.a.s.l with the width varying from 320 to $549 \mathrm{~m}$. The toe of the landslide is partially submerged in the Daxi River, which has a stable water level of 36 m.a.s.l. With an average slope varying from 35 to $60^{\circ}$, the lower and upper parts of the landslide are steep, while the central part is relatively flat. The ravines on both sides of the landslide form their natural boundaries. A tension crack, extending for nearly $400 \mathrm{~m}$ at the crown, constitutes the main scarp of the landslide.

\section{Deformation signs}

The most vulnerable object of this landslide is the Jinwen railway at the toe, which has been the main transportation corridor between Jinhua City and Wenzhou City in Zhejiang Province for the past 30 years. The landslide has not been detected until it began to threaten the railway operation in 2016. As recorded by the locals, a 400 m-long crack was observed at the uppermost part of the landslide after the intensive seasonal rainfall in early 2016 . The main crack is consequently regarded as the crown of the landslide.

Subsequently, more and more active signs have been observed on the ground of the landslide and in the vicinity of the railway. The main scarp behind the uppermost crack reached a vertical displacement ranging from 5 to $50 \mathrm{~cm}$ (Fig. 4a). Some mass collapses were also observed on the loose covering layer near the main crack of the landslide. At the lower part, some transverse cracks were long as $10 \mathrm{~m}$ and their width increased continuously up to $15 \mathrm{~cm}$, indicating the extrusion of the accumulation zone (Fig. 4b). The cracks observed near the left flank represented the shear motion between the stable slope and sliding mass of the landslide at its lateral part (Fig. 4c). Besides, shallow collapses occurred on the ground surface and caused plants or trees to fall (Fig. 4d). Owing to the downward motion of the whole sliding body, the drainage ditch of the railway was destroyed, and the railway was seriously threatened (Fig. 4e).

The aforementioned deformation evidences that the Xiageliao landslide is still active with an increasing displacement over time. A catastrophic collapse may occur
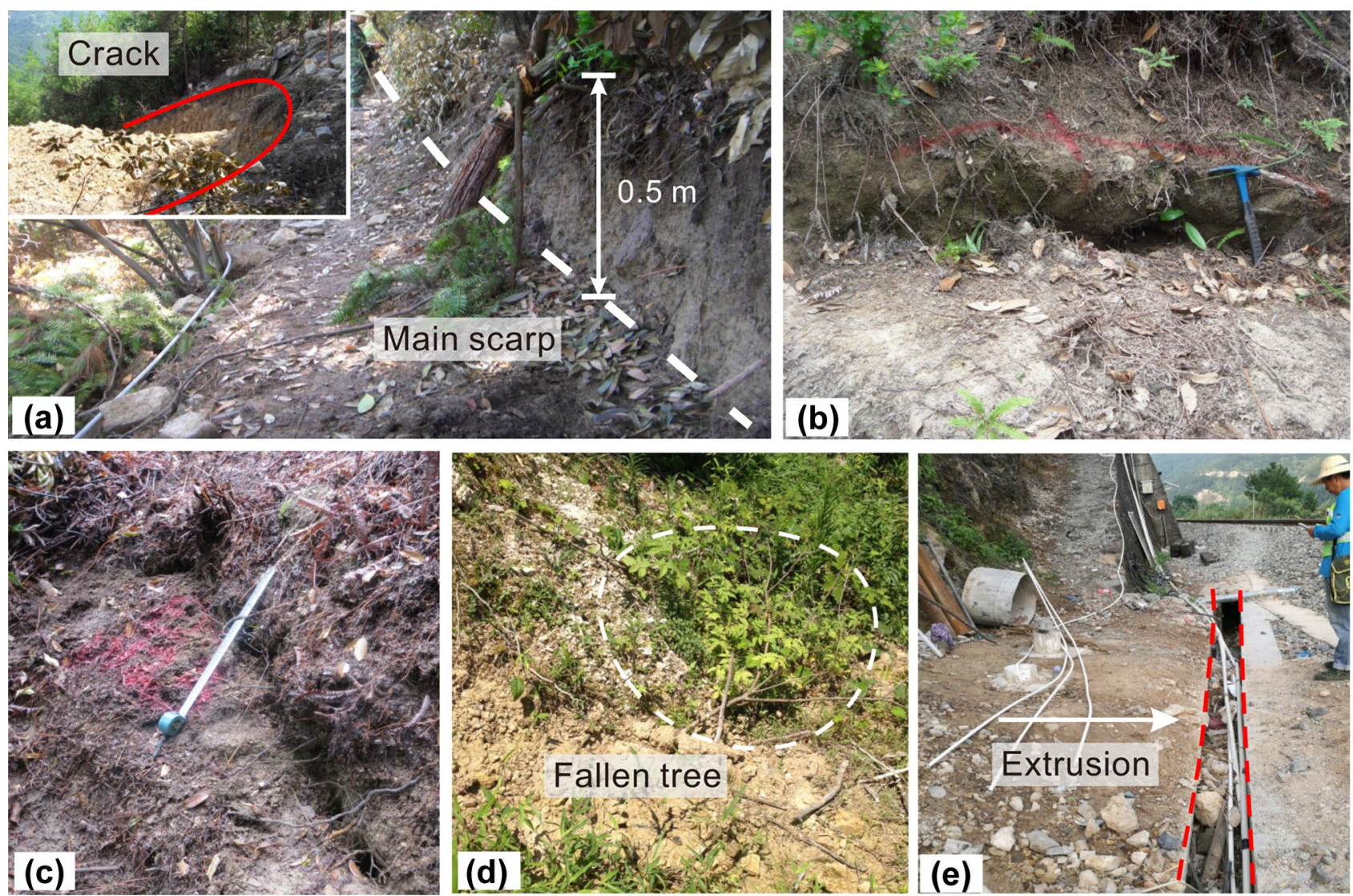

Fig. 4 Representative photos of deformation features on the surface of Xiageliao landslide. The locations are marked in Fig. 2. (a) Main scarp and extension crack at the uppermost part (b) transverse crack at lower slope (c) crack at lateral part (d) shallow collapse at downslope (e) ruined drainage ditch at the toe of the landslide 
under the effects of external forcing, resulting in an unpredictable disaster. For the safety of the Jinwen Railway, some countermeasures are required to carry out for postponing the deformation of the landslide. To this end, the landslide pattern and its triggering factors must be considered.

\section{Material composition}

The geological strata within the site are mainly composed of Quaternary sediments $\left(Q_{4}\right)$ and Lower Cretaceous formation $\left(K_{1 x}\right)$. The landslide area is almost entirely covered by eluvium and colluvial deposits of $Q_{4}$ sediments with a thickness of 0.5 to $3 \mathrm{~m}$. This covering layer consists of silty clay with scattered breccia, and the main source of the breccia is tuff rock from $K_{1 x}$. The Lower Cretaceous formation, consisting of an irregular alternation of $K_{1 x}$ tuff with different degrees of weathering, outcrops at the lower part of the landslide. The geological profile shown in Fig. 5 indicates that, except for the covering layer, the sliding body is mainly composed of $K_{1 x}$ tuff rock. A shear zone was explored at a depth of 30 to $105 \mathrm{~m}$ according to the borehole logs. The soil within the shear zone is composed of grey silty clay with cataclastic breccia. The bedrock of the landslide is slightly weathered $K_{1 x}$ grey tuff.

Figure 6 schematizes the lithostratigraphy from three boreholes at different elevations of the landslide. The tuff layer beneath the thin eluvium deposit is highly irregular chaotic. The alternate tuff layers above the shear zone can be further divided into two sublayers: the intensely fissured and highly weathered tuff at the superficial part; and the moderately weathered tuff with some highly weathered layers interbedded below. The shear zone, composing of a cataclastic material from tuff, is a thick fractured layer with an thickness of $0.6-1.6 \mathrm{~m}$. The soil within the shear zone is defined as clastic soil with its origin from the fully weathered tuff in $K_{1 x}$.

For better understanding of the internal structure of the landslide, an underground tunnel group, including a main investigation tunnel and three auxiliary adits (adit- 1 to adit3 ), was constructed in 2017. The main tunnel has a length of $300 \mathrm{~m}$. The adit- 1 and adit- 3 are both $45 \mathrm{~m}$ long, and the adit- 2 is $35 \mathrm{~m}$ long. The underground tunnel group within the landslide exposed the main shear surface, which is shown in Fig. 7. The slickenside and the interface of sliding mass and bedrock observed in the adits indicate the motion of the shear zone. The adits close to the shear zone can provide sites for the in-situ test. This tunnel group also serves as a countermeasure by draining the underground water.

\section{Groundwater}

The variation of groundwater within the Xiageliao landslide is evaluated by different approaches. The groundwater level increases along with the slope elevation, which is ascertained based on the monitoring of water level of the Daxi River and boreholes. As detected by borehole B2, the

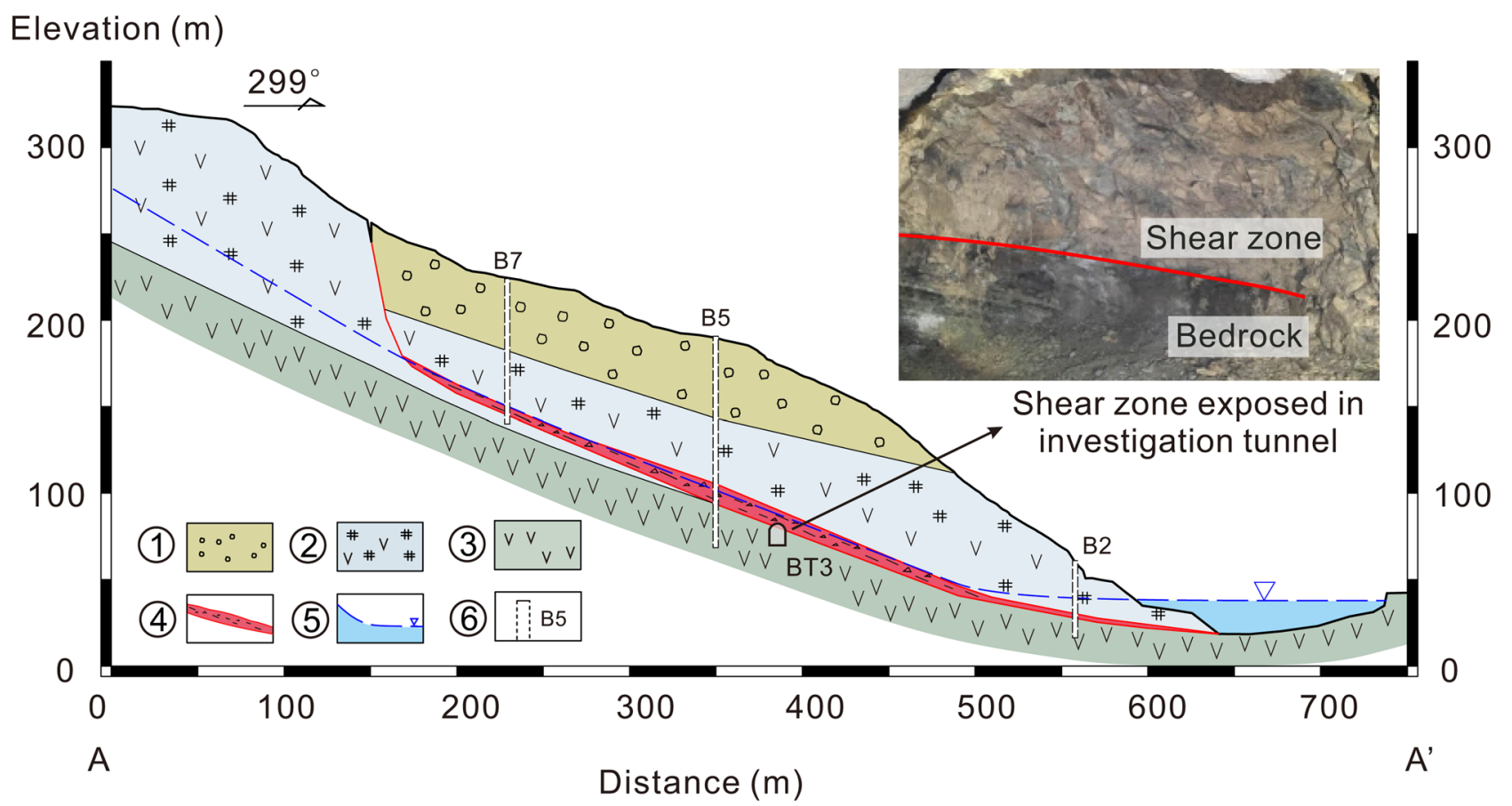

Fig. 5 Profile section A-A' of the Xiageliao landslide with the projection of three boreholes installed with inclinometers. (1) Loose soil and gravel (2) tuff breccia and dense soil (3) intact tuff (4) shear zone (5) water level (6) boreholes 


\section{Borehole B7}

Depth $(\mathrm{m})$

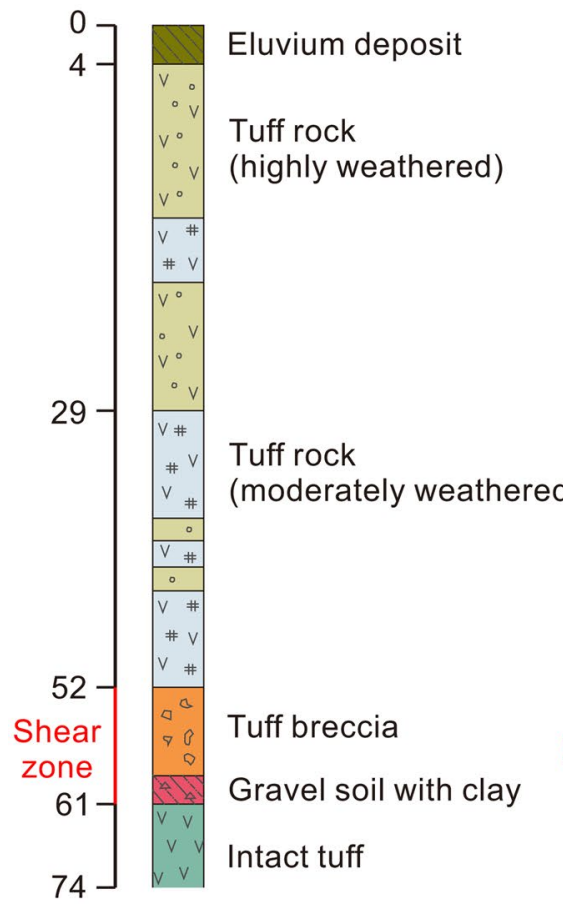

Borehole B5

Depth $(\mathrm{m})$

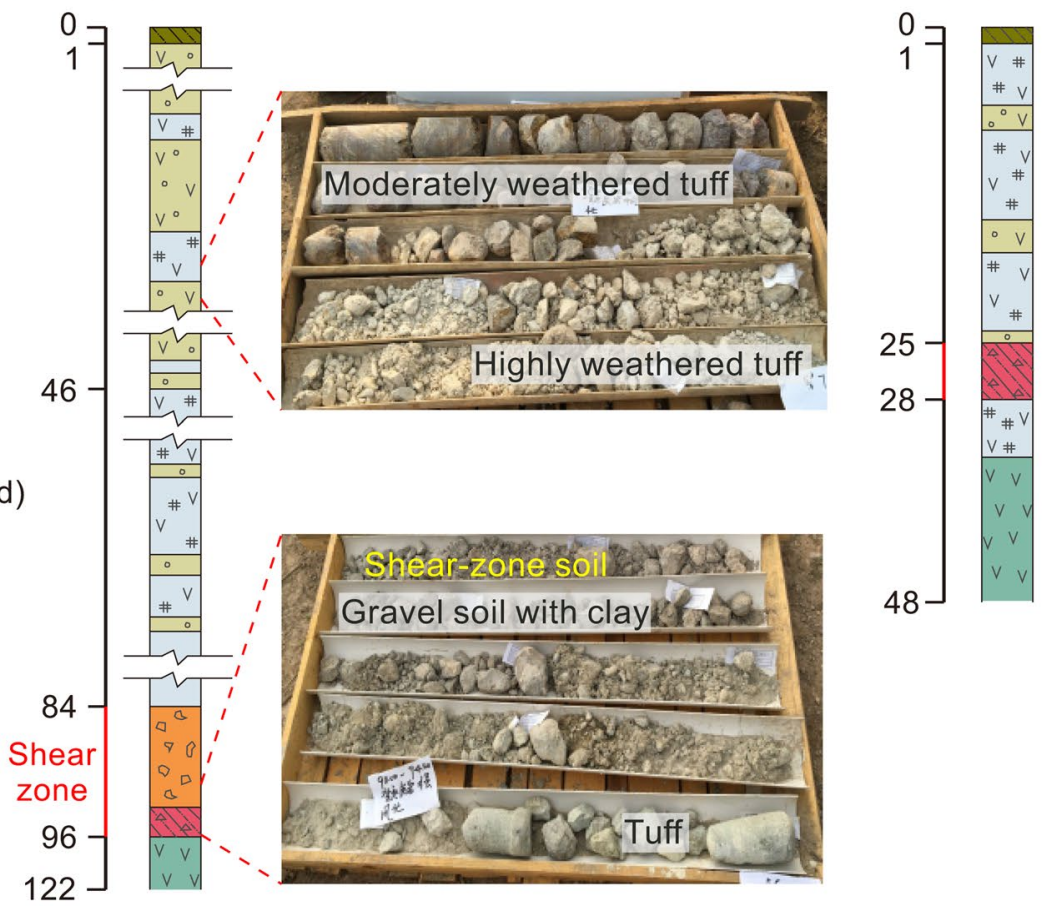

Fig. 6 Lithostratigraphy and borehole samples of the sliding mass

groundwater table at the toe remains above the shear zone during dry seasons. The groundwater is also observed above the shear zone at both flanks of the landslide. At the central part, the groundwater runs through the shear surface, as indicated by the borehole B5. Moreover, groundwater is observed in the sliding mass and near the shear surface (Fig. 8). Note that the water table sketched in Fig. 5 does not present its actual variation in the rainy season since the groundwater is largely affected by infiltration.

\section{Monitoring system}

To investigate the relationship between landslide activity and hydrological features of the landslide, an integrated monitoring system was established in 2016. This system is capable of monitoring deep and superficial displacement, crack development, and underground water table of the landslide. The precipitation data is obtained from the local meteorological department.

\section{Subsurface deformation}

As shown in Fig. 5, three inclinometer probes are installed in the boreholes at the lower, central, and upper parts of the landslide to acquire the subsurface movement. Figure 9 shows the accumulated displacement of the sliding mass during three years. The significant horizontal motion indicates the position of the shear surface in the landslide. The uniform deformation presented in Fig. 9a suggests a basal motion along the shear zone at the lower part of the landslide. In contrast, the mass sliding at the upper part is dictated by a different mechanism. As shown in Fig. 9c, the subsurface movement increases linearly from deep to shallow location. Generally, the superficial displacement of the landslide is continuously increasing over time, while the basal movement at the shear zone remains nearly unchanged. The movement pattern indicates that the viscoplastic deformation accounts for the prevailing movement at the lower part.

According to the inclinometer data, the shear surface at the toe is approximately $27 \mathrm{~m}$ deep from the ground. At the central and upper parts of the landslide, significant displacement is observed in the inclinometers borehole B5 and B7 at the depth of $95 \mathrm{~m}$ and $60 \mathrm{~m}$, respectively. The large deformation clearly indicates the position of the shear surface in the Xiageliao landslide. Moreover, the active zones highlighted in Fig. 9 agree well with the potential shear zones characterized by the borehole logs shown in Fig. 6. Affected significantly by rainy seasons, the deep deformation of the landslide exhibits a timevarying behaviour. The slope mass moves mostly in the spring and summer seasons with more precipitation, while 


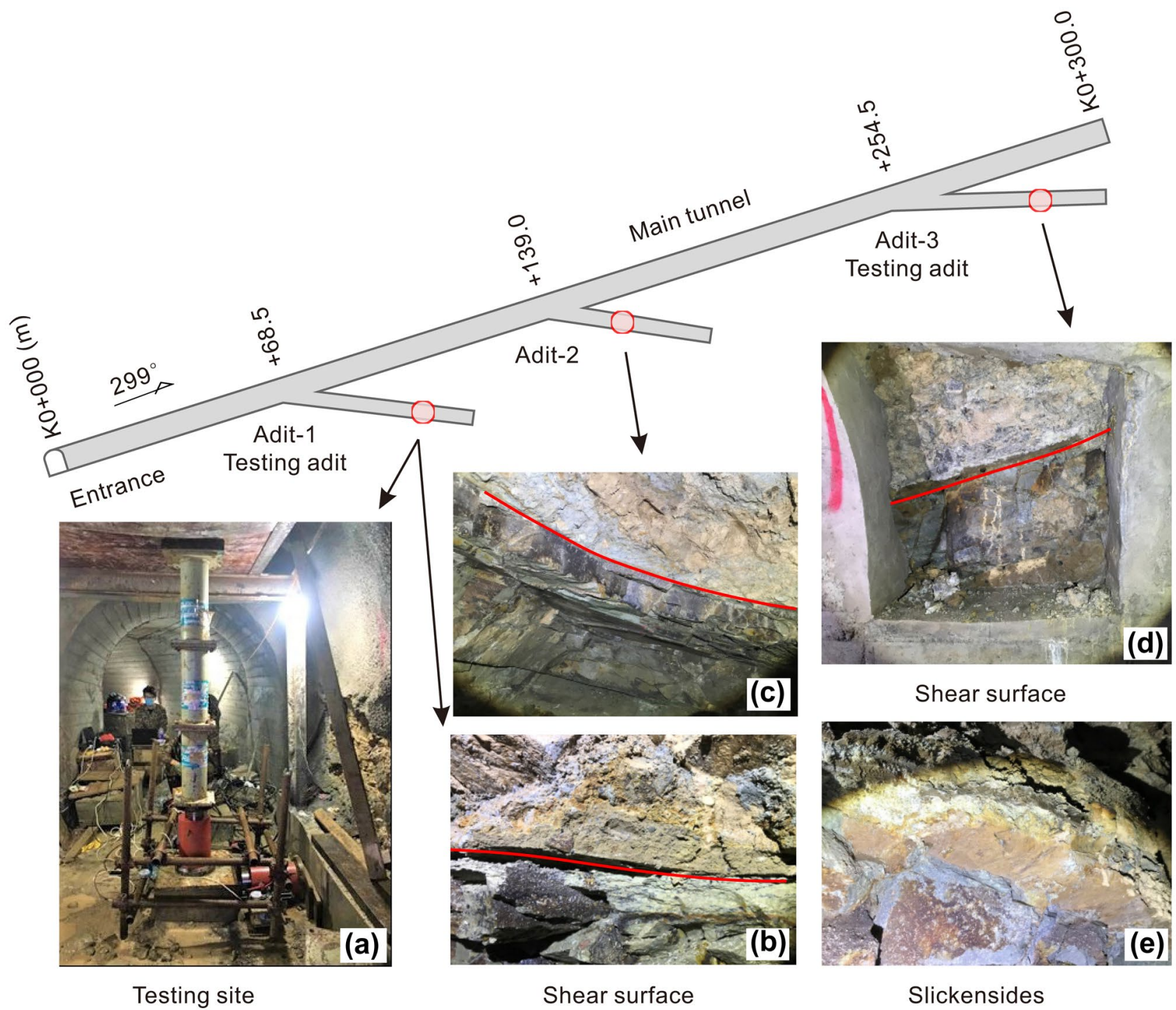

Fig. 7 The in-situ testing site and exposed shear surface by excavating the tunnel group in the landslide. Representative photos were taken in (a, b) adit-1, (c) adit-2, and (d, e) adit-3

the subsurface movement is much smaller during winter seasons with relatively less rainfall. All the evidence indicate that the activity of the landslide is subjected to change with time and is sensitive to the hydrological forcing.

\section{Precipitation and piezometric data}

Figure 10 shows the daily rainfall histogram together with the variation of underground water table at the toe and the
Fig. 8 Observed groundwater in adits. (a) Groundwater existing along with sliding surface and (b) groundwater in the sliding mass
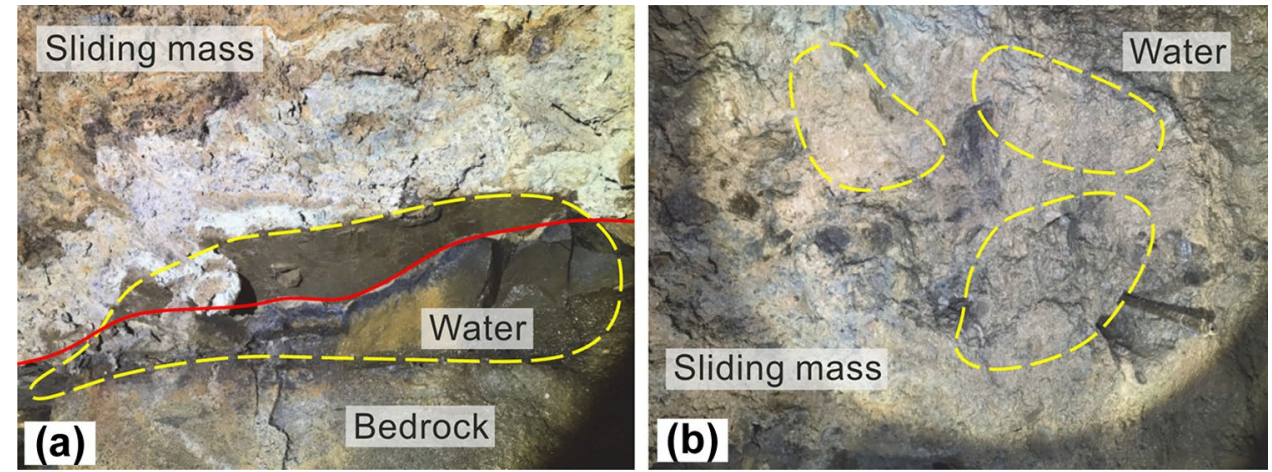


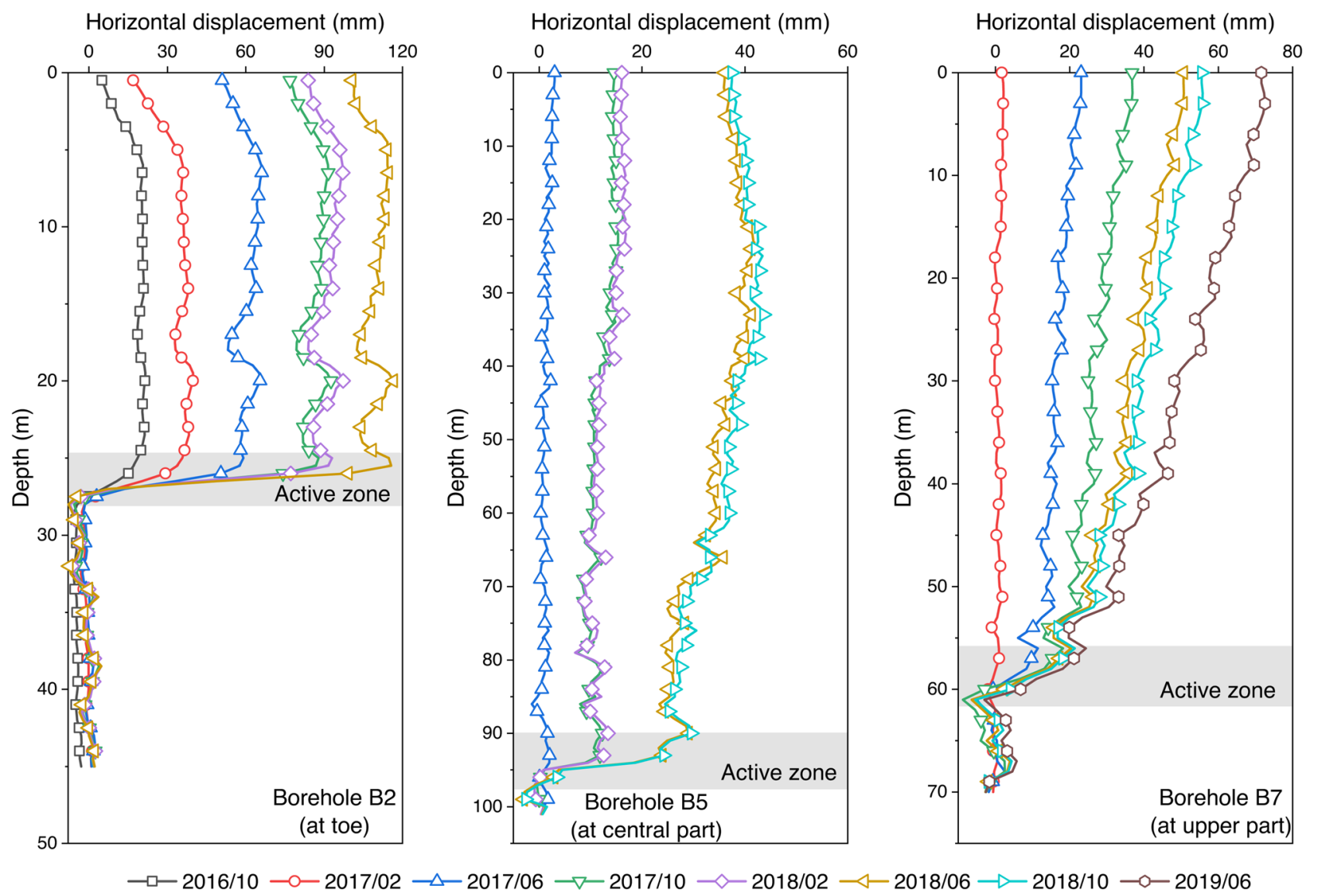

Fig. 9 Subsurface displacement obtained by inclinometer probes

upper part of the landslide. Located near the coastal region, the landslide is influenced by extra hydrological conditions regulated by typhoon events. Table 1 lists the details of typhoons hitting the landslide site from September 2016 to September 2019. The time of these events is also marked in Fig. 10. The magnitude of peak sustained winds reflects the

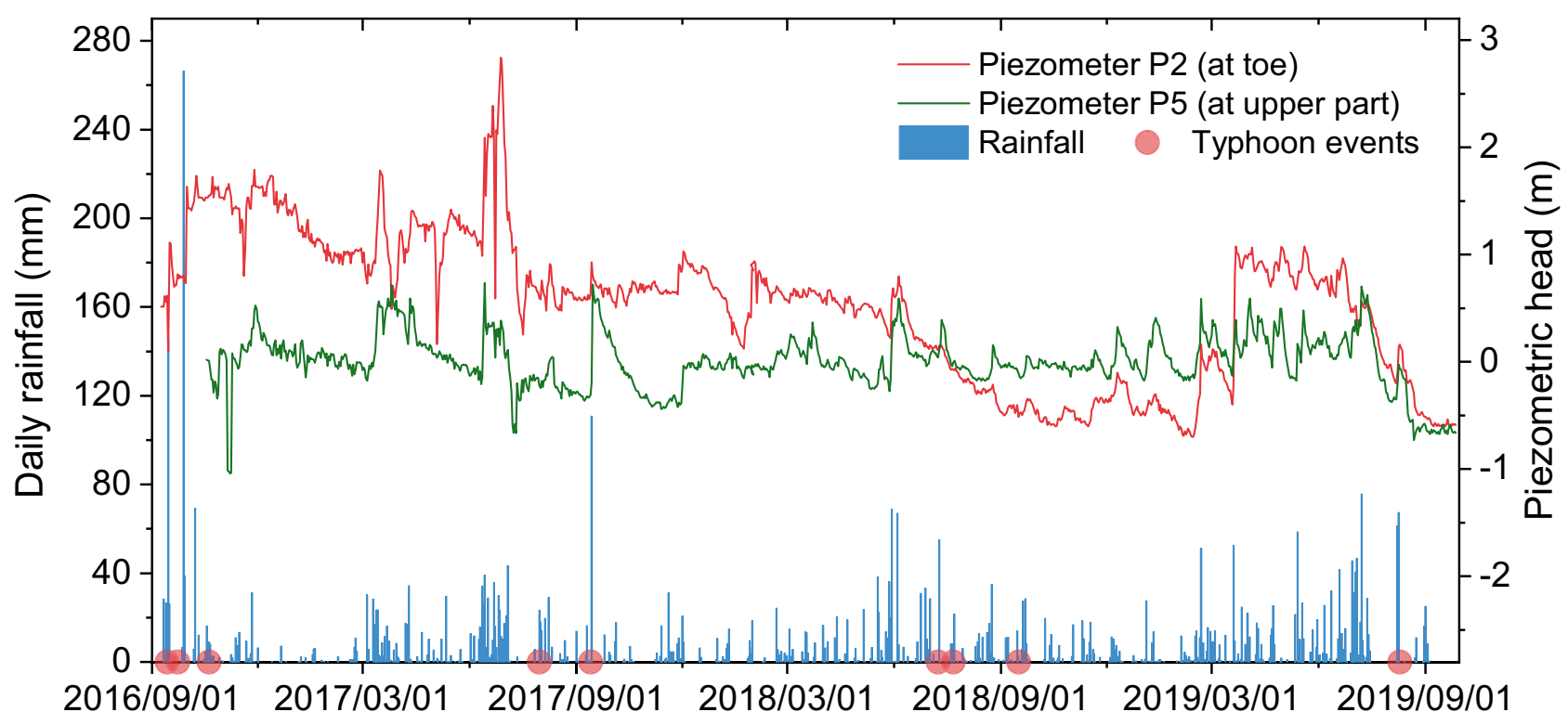

Fig. 10 Daily precipitation and groundwater level changes recorded by piezometer P2 and P5 at the toe and upper part of landslide, respectively 
Table 1 Typhoons passed over the study area during the monitoring period

\begin{tabular}{lll}
\hline Typhoon name & Occurring date & $\begin{array}{l}\text { Peak } \\
\text { sustained } \\
\text { winds* }\end{array}$ \\
\hline Meranti & September $14-17,2016$ & $270 \mathrm{~km} / \mathrm{h}$ \\
Megi & September $23-29,2016$ & $173 \mathrm{~km} / \mathrm{h}$ \\
Haima & October $20-22,2016$ & $151 \mathrm{~km} / \mathrm{h}$ \\
Haitang & July $31-$ August 1,2017 & $65 \mathrm{~km} / \mathrm{h}$ \\
Talim & September $13-16,2017$ & $180 \mathrm{~km} / \mathrm{h}$ \\
Maria & July $9-12,2018$ & $172 \mathrm{~km} / \mathrm{h}$ \\
Ampil & July $22-25,2018$ & $101 \mathrm{~km} / \mathrm{h}$ \\
Mangkhut & September $16-18,2018$ & $162 \mathrm{~km} / \mathrm{h}$ \\
Lekima & August $10-14,2019$ & $187 \mathrm{~km} / \mathrm{h}$ \\
\hline
\end{tabular}

intensity of the typhoon events. It also indirectly suggests the cumulative precipitation induced by typhoon events. During the late summer and early autumn, these tropical cyclones usually bring torrential rainfall to the landslide site, which accounts for the majority of annual precipitation. Another important precipitation source is the seasonal rainfall from spring to summer, which features low intensities with long duration.

Clearly, the rainfall events cause significant variation in the groundwater table, which is measured by two piezometers located at the toe (piezometer P2) and the upper part (piezometer P5) of the landslide. As shown in Fig. 10, the groundwater table at the toe is more sensitive to external forcing and has larger fluctuations compared to that at the upper part. The curve obtained by piezometer P5 exhibits a synchronous impulse with rainfall events. After an intensive precipitation, the groundwater table at the toe drops quickly, whereas the one at the upper part returns slowly to the original level.

It is speculated that these different responses to the precipitation can be attributed to the different buried depths of groundwater table in the landslide body. Since the groundwater table at the toe of the landslide is close to the ground surface, its response to external hydrological forcing is much faster than the one given by the upper part. Moreover, the slope toe is adjacent to the Daxi river, and hence, the groundwater level is inevitably affected by the river water level during rainy seasons. Conversely, the landslide covers with thick sliding mass at the upper part. Based on this reasoning, the groundwater is predominantly influenced by the infiltration from rainwater and shows a delayed response to rainfall events.

\section{Crack deformation}

A 400-m-long main crack at the crown indicates the tensile deformation of the landslide. The development of this crack is monitored by several crackmeters instrumented vertically to the dip of the crack. As shown in Fig. 11, the cumulative displacement of the crack exhibits a stepwise pattern, featured by episodic accelerations and decelerations. The ellipse shadows in Fig. 11 highlight the accelerated stages of crack propagation from March to September, corresponding to the wet seasons. In dry seasons, the crack remains dormant until the next enduring precipitation initiating the landslide motion.

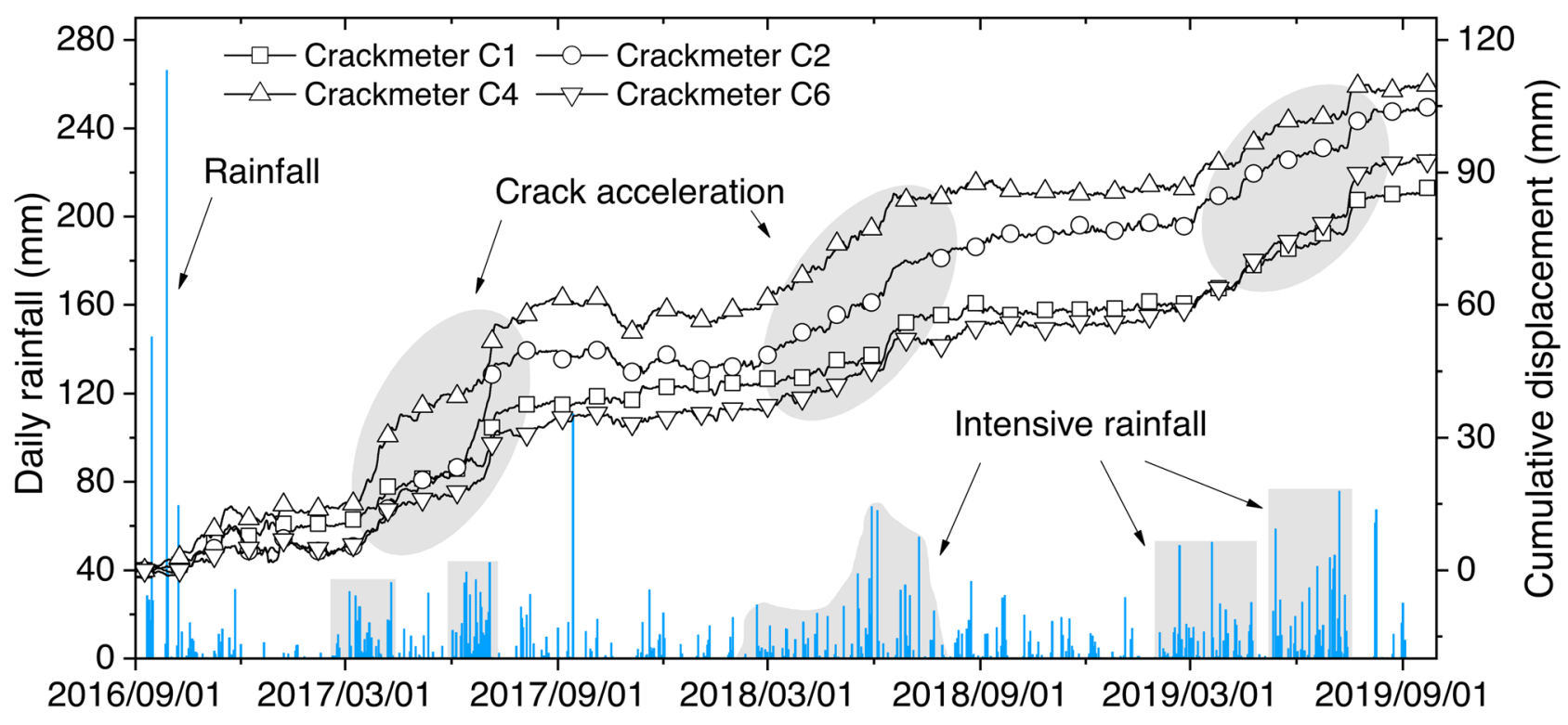

Fig. 11 Main crack development curves recorded by crackmeter C1, C2, C3, and C4 with daily precipitation 
Under the effect of infiltration, the main crack extends with an average displacement rate of more than $30 \mathrm{~mm} / \mathrm{year}$. The largest deformation is observed at the middle of the crack (see Fig. 3), and this dramatic tension leads to an accumulative deformation of $110 \mathrm{~mm}$ from 2016 to 2019 (see the crackmeter C4 in Fig. 11). According to the data logged by these crackmeters, the extension of the main scrap offers direct evidence of the landslide process, which is largely affected by the infiltration of rainfall.

\section{Superficial displacement}

The superficial displacement of the landslide is evaluated by a GNSS monitoring network, and the positions of seven GNSS points are given in Fig. 3. In addition, a satellite positioning reference station is set on the stable bedrock on the other side of the Daxi River. The time interval of data acquisition of this GNSS monitoring network is two times per day. The accuracy of the GNSS monitoring network is $2.5 \mathrm{~mm}$. The result of superficial monitoring is shown in Fig. 12, together with the daily precipitation. All monitoring curves indicate that the superficial displacement of the landslide features a stepwise movement pattern, with a similar tendency to the development of the main crack. According to the crackmeters and GNSS monitoring, it can be concluded that the landslide is undergoing two alternate moving stages: an active stage corresponding to seasonal and typhoon bound rainfall, and a dormant stage during dry seasons.

The superficial monitoring results suggest that the active stages account for the major deformation of the whole landslide motion. The accumulated movement of the landslide leads to a displacement rate of approximately $80 \mathrm{~mm} / \mathrm{year}$. According to Varnes (1978), this landslide can be categorized as a slow-moving landslide. It is obvious that the active stages of the landslide are initiated by the enduring rainfall. As shadowed in Fig. 12, some over 10-day rainfall events, like March and June in 2017, and June in 2018, induce dramatic growth in the surface displacement. Similarly, the continuous motion of the landslide from March to July in 2019 agrees well with the intermittent rainfall occurred at the same time. Normally, the landslide exhibits a delayed response to rainfall events, and after these long-duration precipitations, it recovers to dormant stages.

Some remarkable episodic rainfall events also seem to affect the landslide process. For instance, a $260 \mathrm{~mm}$ rainfall event occurred in September 2016 after two typhoons, followed by a movement of $42 \mathrm{~mm}$. Another downpour in September 2017 with an intensity of $110 \mathrm{~mm} /$ day gave rise to slight impaction on the landslide process. The different responses of the landslide to these two episodic rainfall events may be attributed to the antecedently accumulated precipitation. In September 2016, the antecedent precipitation, the torrential rainfall over $260 \mathrm{~mm} / \mathrm{day}$, and the subsequent precipitation all account for the triggers leading to an obvious movement of the landslide in early October 2016. In September 2017, the episodic rainfall only occurred one day after Typhoon Talim passed by, whereas the landslide can hardly be influenced under this transient condition. Thus, the landslide movement is more predominantly affected by the enduring precipitation than the episodic rainfall events with high intensities. Additionally, the long-duration infiltration generated by enduring precipitation facilitates the interaction between rainwater and shear zone, and this process will be

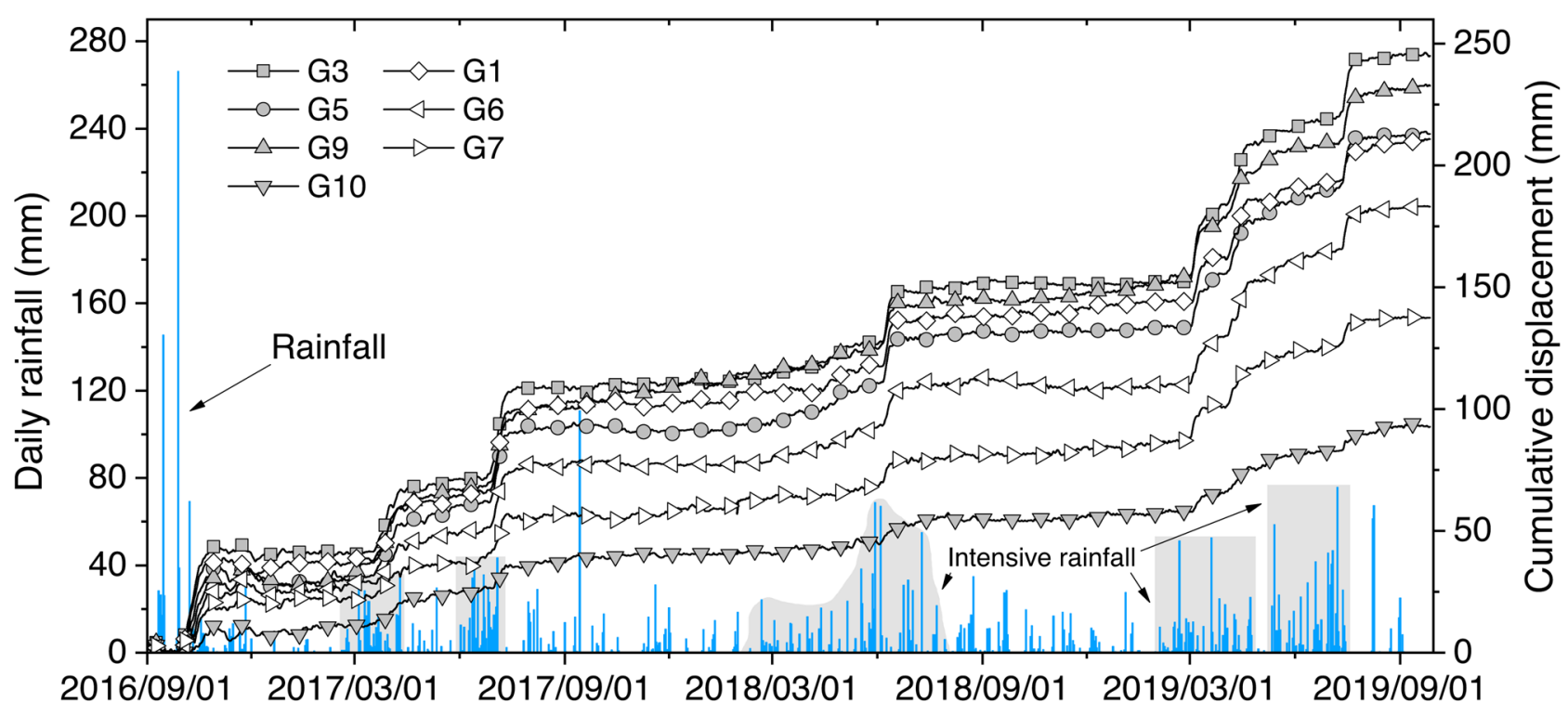

Fig. 12 Horizontal displacement recorded by GNSS points together with daily precipitation 
easily prolonged according to the low permeability and long seepage path of sliding mass of some deep-seated landslides (Prokesova et al. 2012; Rosone et al. 2018).

The activity intensities of different parts of the landslide are also drawn from the monitoring results. Four GNSS points (G3, G5, G9, and G10) installed along with the A-A' section suggest a significant deformation at the lower part of the landslide. Particularly, the monitoring point G3 records the largest cumulative displacement, indicating the most active motion taken place near the toe. As shown by GNSS points G1 and G6, the lateral parts have less activity compared to the middle part. Close to the main crack, the uppermost part accumulates only $93 \mathrm{~mm}$ displacement. The intensive activity at the toe is, on one hand, as a result of the enhanced soil-water interaction occurred in the shear zone. On the other hand, the extrusion from the upper part also generates a cumulative effect on the deformation of the lower part. Furthermore, the undercutting of the river bank is likely to have some destabilizing effects on the landslide movement.

\section{Experimental investigation}

All the monitoring results show that the landslide undergoes severe deformation from 2016 to 2019 . The subsurface monitoring result suggests that the displacement along basal shear zone attributes to the major motion of the whole landslide, and rainfall significantly affects the acceleration of the landslide process. This field observation leads to the necessity of performing experiment to explore the mechanism behind the soil-water interaction within the shear zone. Therefore, an experimental investigation, including in-situ and laboratory direct shear tests, was carried out to study the process of interplay between the rainwater and shearzone soil.

\section{Test material and preparation}

The excavation of the tunnel group exposed the shear zone in both adit- 1 and adit- 3 . The one in adit- 1 is mainly composed of fractured breccia, whereas the other in adit- 3 contains higher proportions of clay-like materials. Some intact soil samples were taken from these two adits to obtain the general physical properties. As presented in Table 2, the intact soil samples show different properties. The soil in adit-3 has a higher plasticity index, implying that the soil is richer in clay minerals. Considering the non-uniformity of the shear-zone soil, both adit- 1 and adit- 3 were selected as the testing sites for the in-situ tests. The soils sampled in both sites were also used for the laboratory direct shear tests.

The in-situ direct shear apparatus is composed of a shear box, reaction frame, and servo-controlled system with hydraulic jacks. For the sake of simplicity, only an upper shear box with a dimension of $0.5 \times 0.5 \times 0.25 \mathrm{~m}$ is utilized as the shear box. The shear-zone soils exposed in the adit- 1 and adit- 3 are prepared into block samples with the dimension slightly smaller than the shear box. The shear plane is the interface between the block sample and the soil beneath the ground. To this end, the ground around the block sample is flatly grouted before the shear box is settled on the ground. After then, wet sand is used to fill the gap between block samples and the shear box. During the test, the normal stress is imposed by applying a vertical load on the samples. The test is then initiated by applying a constant shear displacement on the shear box in horizontal direction. The test is terminated when the horizontal displacement reaches $50 \mathrm{~mm}$, or the failure occurs in the sample. The in-situ sample preparation and the setup of the test are shown in Fig. 13.

After the in-situ tests, the disturbed soils in the block samples are collected for the laboratory direct shear tests. The soils are first air-dried and then sieve to keep only fine particles less than $2 \mathrm{~mm}$. These particles are mixed with water to reach a water content close to the in-situ state. Since the water content can largely influence the strength of the soil, homogenous water content is desirable to gain. For this purpose, the prepared soil are stored in a covered container for several days. The soil are compacted into round specimens (round area of approximately $30 \mathrm{~mm}^{2}$ and height of $20 \mathrm{~mm}$ ) to achieve the desired density close to the natural state.

\section{Test plan}

Two test scenarios, including natural and wet conditions of the samples, are designed to investigate the mechanical behaviours of the soil. In the in-situ test, the original state of the samples is considered as the natural condition, while the wet condition is attained by wetting the block samples for 20 days. In the laboratory, the aforementioned specimens are regarded in the natural state, whereas some specimens
Table 2 Basic properties of the shear-zone soils

\begin{tabular}{lllllll}
\hline Sample locations & $\rho\left(\mathrm{g} / \mathrm{cm}^{3}\right)$ & $e$ & $W(\%)$ & $W_{L}(\%)$ & $W_{P}(\%)$ & $I_{P}$ \\
\hline adit-1 & 2.05 & 0.58 & 23.0 & 25.1 & 18.5 & 6.1 \\
adit-3 & 1.84 & 0.75 & 17.5 & 19.0 & 12.9 & 10.1 \\
\hline
\end{tabular}

$\rho$ bulk density, $e$ void ratio, $W$ water content, $W_{L}$ liquid limit, $W_{P}$ plastic limit, $I_{P}$ plasticity index 
Fig. 13 (a) Shear-zone soil samples and (b) in-situ direct shear apparatus. Photos were taken in adit-1
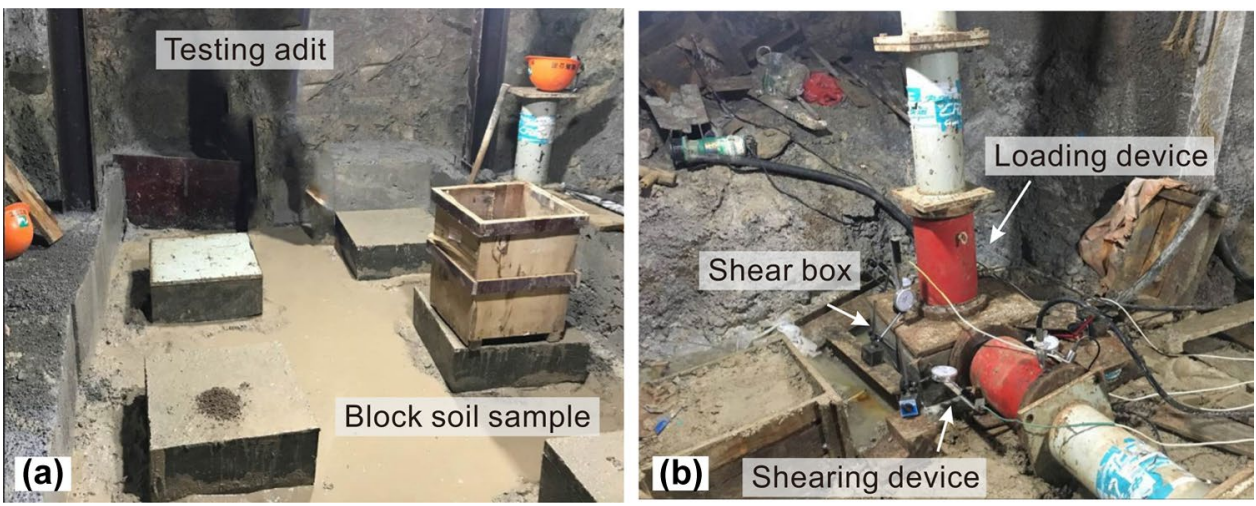

are waded into distilled water with different durations. These conditions mimic the interaction between shear-zone soils and rainwater during landslide motion at the dormant and active stages in dry and rainy seasons, respectively. The detailed programme of the tests is presented in Table 3.

\section{Test result}

Figure 14 shows the result of the in-situ direct shear tests. Clearly, the soil in adit-1 yields a greater shear strength. The cohesions obtained under both wet and natural test conditions are approximately 10 times larger than those in adit-3. The soil in adit-1 at relatively low effective normal stress, i.e. $400 \mathrm{kPa}$ and $450 \mathrm{kPa}$, attains a similar shear strength under the two testing conditions. Note that only two results are obtained in adit-3 under the wet condition due to a technical problem of the apparatus. Nevertheless, an obvious reduction in the shear strengths is observed in the block samples at both adits after the wetting treatment. The inspection of the in-situ test suggests that two shear-zone soils exhibit a great variation in shear strength. Such a remarkable difference among these results may be due to the higher breccia content of the shear zone in adit-1. Moreover, the clay content and coarse particles within the soil may also contribute to this diversity in shear strength (Skempton 1985; Maio et al. 2013; Wang et al. 2020).
The strength envelopes of two soils obtained from the laboratory direct shear tests are presented in Fig. 15. The shear strengths of reconstituted soils are significantly different from those obtained in the field. Despite being taken from different positions of the landslide, the two soils show similar shear behaviours. This phenomenon may be due to the fact that all the tested soils are reconstituted without coarse particles. Similar to the in-situ test, the wet treatment results in a significant reduction in the shear strength of the soils. As shown in Fig. 15a, the reduction in shear strength of the soil in adit-1 is observed mainly in the first 15 days of wetting treatment. The soil in adit- 3 remains a longer interaction with water (Fig. 15b). It is found that the shear strength decreases continuously even after 30-day wetting. The difference in shear resistances of the shear-zone soils can be linked to the landslide movement since the superficial deformation of different locations usually presents variable velocities.

\section{Discussions}

\section{Time-dependent soil-water interaction}

The strength reduction in both laboratory and in-situ tests indicates that the soil-water interaction plays a key role in weakening the shear zone, and this interplay is
Table 3 The testing plan of the in-situ and laboratory direct shear tests

\begin{tabular}{|c|c|c|c|c|}
\hline Tests & Locations* & Test conditions & Normal stress $(\mathrm{kPa})$ & $\begin{array}{l}\text { Shearing } \\
\text { rate }(\mathrm{mm} / \\
\mathrm{min})\end{array}$ \\
\hline \multirow[t]{2}{*}{ In-situ } & adit-1 & $\begin{array}{l}\text { natural state } \\
\text { wet for } 20 \text { days }\end{array}$ & $400,450,500,600,700$ & 0.05 \\
\hline & adit-3 & $\begin{array}{l}\text { natural state } \\
\text { wet for } 20 \text { days }\end{array}$ & $\begin{array}{l}100,200,250,275,300 \\
50,75\end{array}$ & \\
\hline \multirow[t]{2}{*}{ Laboratory } & adit-1 & $\begin{array}{l}\text { natural state } \\
\text { wet for } 5 \text { - } 60 \text { days }\end{array}$ & $100,200,300,400$ & 0.02 \\
\hline & adit-3 & $\begin{array}{l}\text { natural state } \\
\text { wet for } 5 \text { - } 60 \text { days }\end{array}$ & & \\
\hline
\end{tabular}

*Locations for the in-situ test and soil sampling 

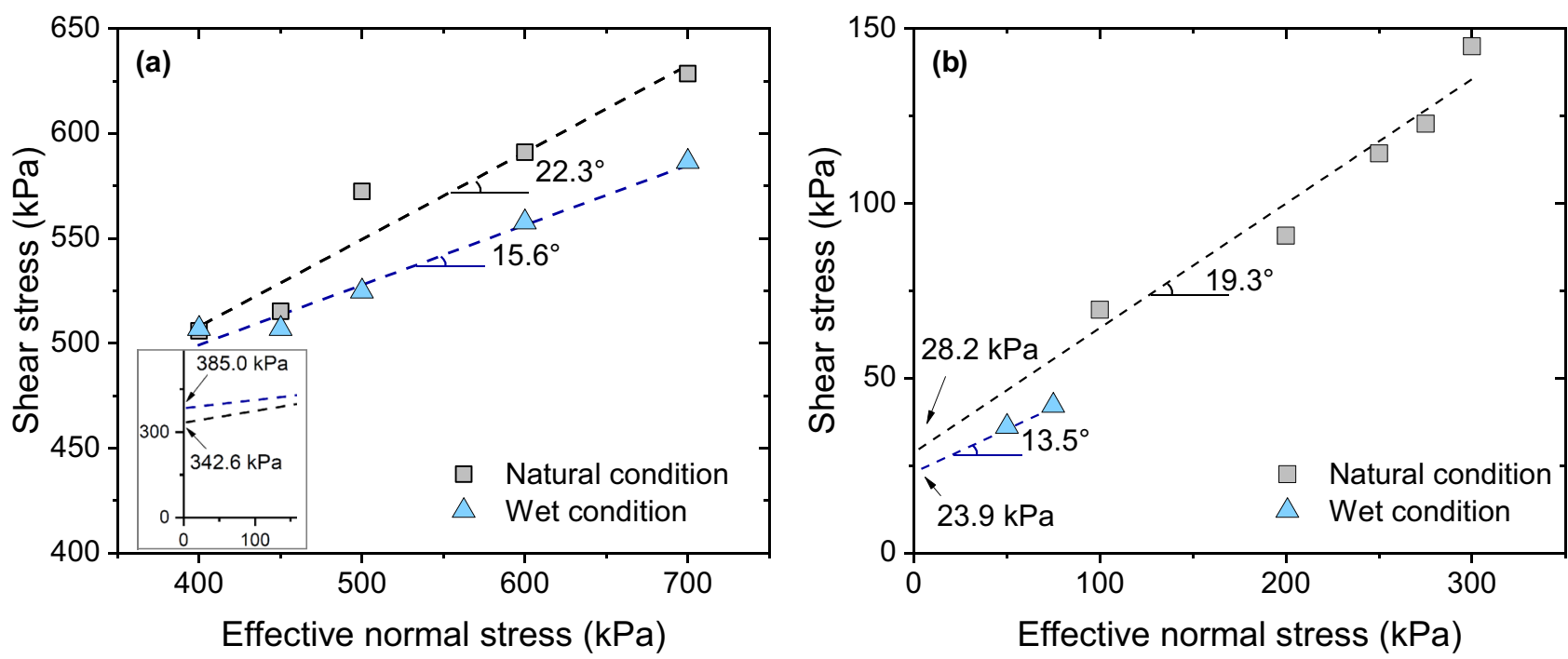

Fig. 14 The results of the in-situ direct shear tests carried out in (a) adit-1 and (b) adit-3 under both natural and wet conditions

time-dependent. In other words, the landslide activity exhibits a time-dependent response to the rainfall.

Figure 16 illustrates the variation of cohesion and friction angle after wet treatment of these two soils in both laboratory and in-situ tests. Generally, the soil in adit-1 yields higher shear strength than that in adit-3 at the natural state. The wet treatment, however, gives rise to a timedependent reduction in both cohesion and friction angle. It
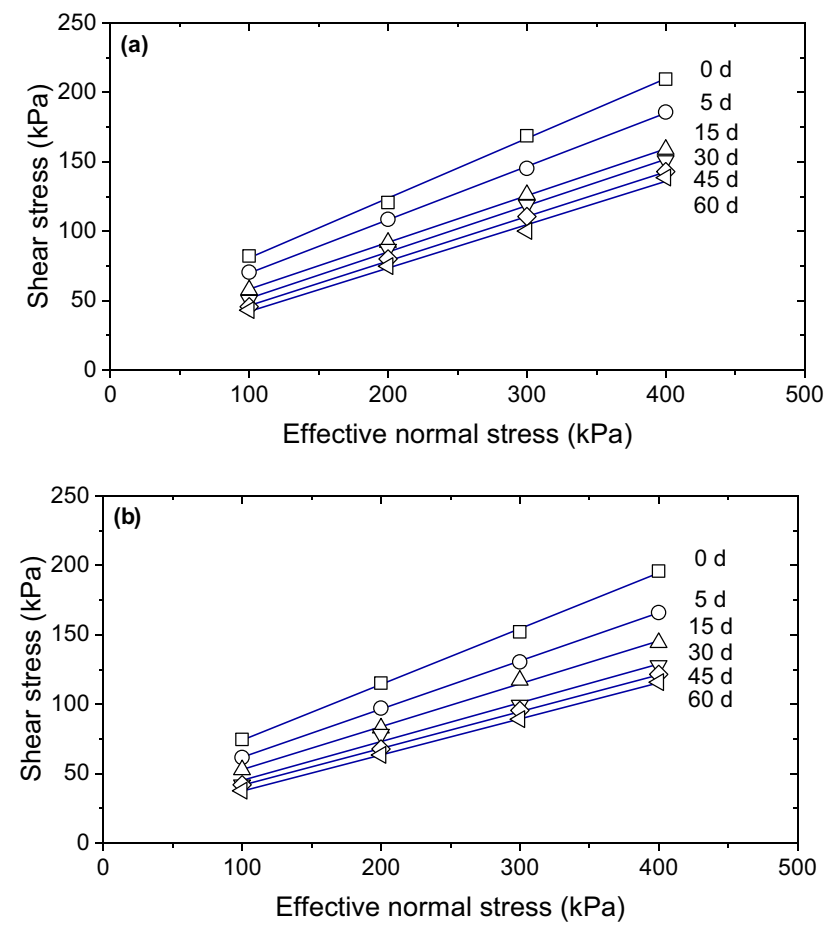

Fig. 15 Strength envelopes of shear-zone soil (a) adit-1 and (b) adit-3 is observed from the laboratory tests that the cohesion of both soils reduced approximately $25 \mathrm{kPa}$ after 60 -day wetting (Fig. 16a). Note that the cohesion of the natural soil in adit- 1 shows an abnormal increase after 20-day wetting. This scattered result, commonly observed in in-situ tests, may be attributed to the heterogeneity of the intact soil samples (Springman et al. 2003; Fannin et al. 2005).

For the friction angle, the wetting condition leads to more reduction in the field. For example, the friction angles of soils reduce $6^{\circ}$ after 20-day wetting in the in-situ tests, while the laboratory tests induce only half of such decrease after 20-day wetting. In the laboratory, the time-dependent behaviour of soil indicates that the reduction of friction angles slows down after 15-day and 30-day wetting for the soils in adit- 1 and adit-3, respectively. This observation agrees well with the analysis of shear strength weakening shown in Fig. 15. As a consequence, the friction angle is more effectively influenced by the soil-water interaction and dominates the strength behaviour of the shear-zone soil, which is also observed in the experimental works of other deep-seated landslides (Xu et al. 2015; Liu et al. 2020).

The difference of shear-zone soil between in-situ and laboratory observations has long been discussed by many authors (Springman et al. 2003; Lunne et al. 2006). In our case, the variation of the shear strength with wetting duration evidences that the strength reduction of the shear zone due to the soil-water interaction is time-dependent. The wetting of soil may give rise to some strength reduction, which is manifested at the micro-scale by some changes in mineral aggregates, intergranular voids, and orientation of the soil particles (Hu et al. 2018b; Kang et al. 2020). This experimental results may be used to explain the phenomenon that the landslide still undergoes displacement at its 

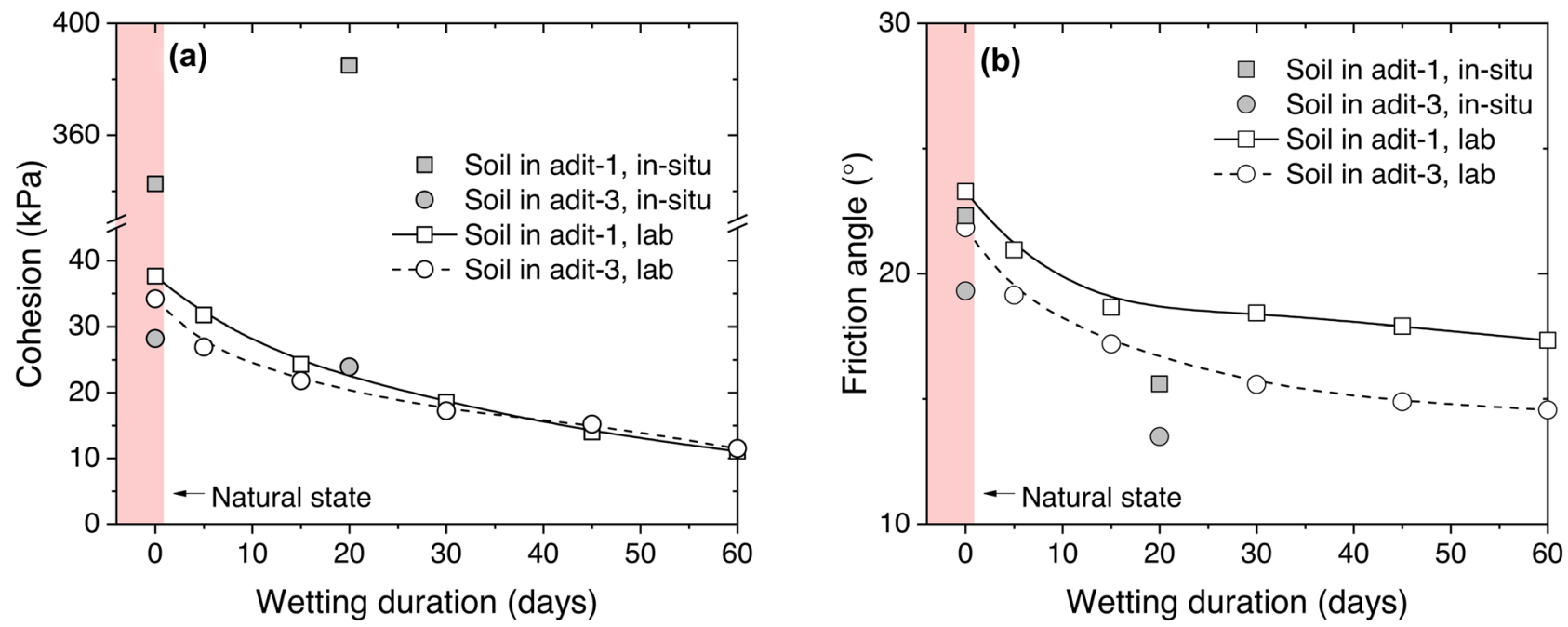

Fig. 16 Variation against wetting duration of (a) cohesion and (b) friction angle

dormant state. Additionally, the antecedent rainfall with a long duration may continuously weak the shear zone during the landslide dormancy.

\section{Soil-water interaction affecting landslide motion}

Previous studies (Zezere et al. 2005; Scaringi 2016) show that the enduring precipitation may lead to deep displacement along the shear zone by reducing the strength of the soil. Our experimental work indicates that the fastest decrease of shear strength occurs in the early days of wet treatment. In the real situation, landslides may not give hairtrigger feedback to the rainfall. Instead, a delayed response is normally observed, regulated by the stress state near the shear zone, the buried depth of the shear zone, and the permeability of the overlying material (Scaringi and Di Maio 2016; Scaringi et al. 2018b). As illustrated in Fig. 17, the landslide motion is predominantly initiated by rainfall and related to the soil-water interaction, which is also verified by the monitoring result.

Fig. 17 The sketch of landslide process initiated by rainfall
After the precipitation, the pore water within the shear zone begins to discharge, resulting in an increase of the effective stress in the shear zone. The shear-zone soil may undergo reconsolidation during the dormant state. This process usually occurs when the soil is at rest or static stage with overlying stress, and it also gives rise to some strength regain in the shear zone (Stark and Hussain 2010; Bhat et al. 2013; Hu et al. 2018a). The consolidation in the shear zone usually leads to an apparent cohesion, which is easily disturbed by the external forcing (Schofield 2006). As a matter of fact, the regained strength induced by consolidation of the soil is hard to be measured in a real landslide. Some scholars point out that the strength generated by consolidation of the soil is not enough to counteract the impaction induced by the external forcing like rainfall, as also experimentally observed in the literature (Gibo et al. 2002; Wang et al. 2018). This perspective can be linked to the monitoring observations. Despite the regained strength of the shear-zone soil, the long dormant stage will be terminated by the subsequent rainy season, then the landslide is motivated to deform again.

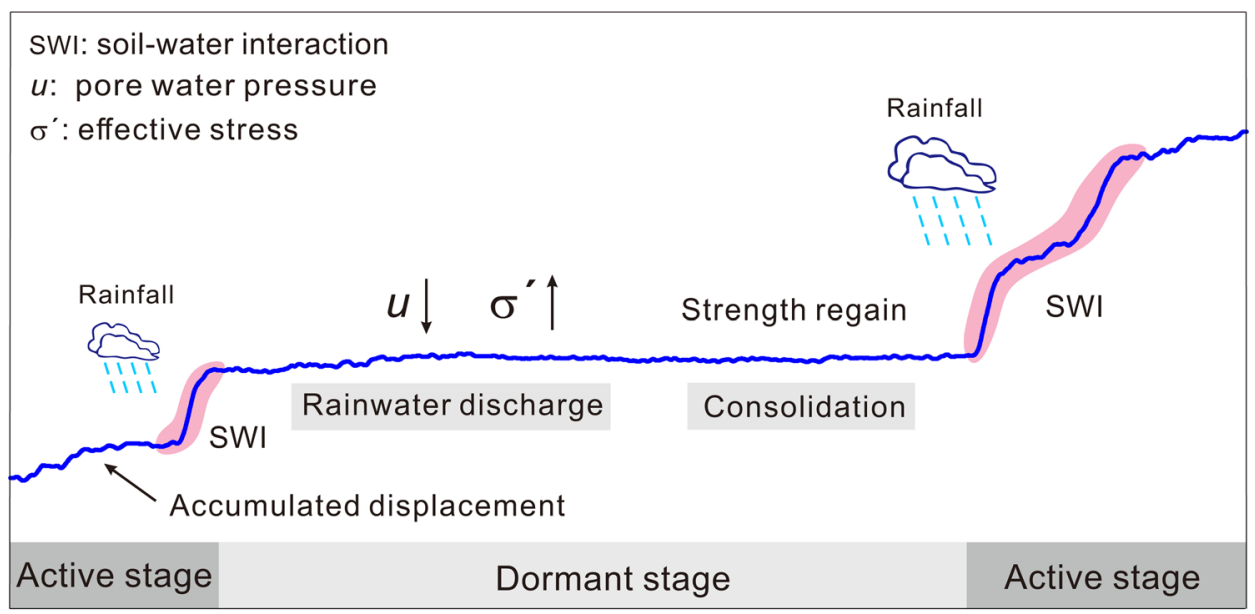




\section{Conclusions}

In this paper, the role of soil-water interaction in regulating the movement of a deep-seated landslide is investigated based on in-situ observation, field monitoring, in-situ and laboratory experiments.

The observed deformation at the main scarp indicates that the landslide is very active and sensitive to rainfall. Based on our monitoring since 2016, the landslide deformation exhibits a stepwise slow-moving pattern, characterized by alternate active and dormant stages. The monitoring result suggests that the landslide movement is linked to seasonal and typhoon-triggered rainfall. The monitoring further shows that more accumulated displacement is induced by the enduring precipitation than by the episodic rainfall with short durations.

An inspection of the in-situ and laboratory tests reveals that the shear-zone soil experiences a significant reduction in shear strength due to the soil-water interaction. The strength reduction is particularly noticeable in the first 30-day wetting. Moreover, wetting reduces both cohesion and friction angle of the shear-zone soil. This mechanism is thought to be responsible for the initiation of the landslide and brings the landslide from a dormant stage to an active stage.

Acknowledgements This work was funded by National Natural Science Foundation of China (No. 41772314), the H2020 Marie Skłodowska-Curie Actions RISE 2017 HERCULES (No. 778360), and FRAMED (No.734485). The second author wishes to thank the Otto Pregl project "Kriechhange" for financial support in Austria.

Author contributions Ms. Xuan Kang and Dr. Shun Wang contribute equally to this work: writing-original draft, conceptualization, and review and editing. Prof. Wei Wu and Prof. Guangli Xu performed supervision. The rest authors provide material and data.

Funding Open access funding provided by University of Natural Resources and Life Sciences Vienna (BOKU).

\section{Declarations}

Competing interest The authors declare that they have no known competing financial interests or personal relationships that could have appeared to influence the work reported in this paper.

Open Access This article is licensed under a Creative Commons Attribution 4.0 International License, which permits use, sharing, adaptation, distribution and reproduction in any medium or format, as long as you give appropriate credit to the original author(s) and the source, provide a link to the Creative Commons licence, and indicate if changes were made. The images or other third party material in this article are included in the article's Creative Commons licence, unless indicated otherwise in a credit line to the material. If material is not included in the article's Creative Commons licence and your intended use is not permitted by statutory regulation or exceeds the permitted use, you will need to obtain permission directly from the copyright holder. To view a copy of this licence, visit http://creativecommons.org/licenses/by/4.0/.

\section{References}

Agliardi F, Scuderi MM, Fusi N, Collettini C (2020) Slow-to-fast transition of giant creeping rockslides modulated by undrained loading in basal shear zones. Nat Commun 11(1):1-11. https://doi.org/ 10.1038/s41467-020-15093-3

Bhat DR, Yatabe R, Bhandary NP (2013) Study of preexisting shear surfaces of reactivated landslides from a strength recovery perspective. J Asian Earth Sci 77:243-253. https://doi.org/10.1016/j. jseaes.2013.08.023

Bossi G, Schenato L, Marcato G (2017) Structural health monitoring of a road tunnel intersecting a large and active landslide. Appl Sci 7(12):1271. https://doi.org/10.3390/app7121271

Corominas J, van Westen C, Frattini P, Cascini L, Malet JP, Fotopoulou S, Catani F, Van Den Eeckhaut M, Mavrouli O, Agliardi F, Pitilakis K, Winter MG, Pastor M, Ferlisi S, Tofani V, Hervas J, Smith JT (2014) Recommendations for the quantitative analysis of landslide risk. Bull Eng Geol Environ 73:209-263. https://doi.org/10.1007/ s10064-013-0538-8

Crosta GB, Frattini P (2008) Rainfall-induced landslides and debris flows. Hydrol Process 22(4):473-477. https://doi.org/10.1002/ hyp. 6885

Dawson EM, Roth WH, Drescher A (1999) Slope stability analysis by strength reduction. Geotechnique 49(6):835-840. https://doi.org/ 10.1680/geot.1999.49.6.835

Fannin RJ, Eliadorani A, Wilkinson JMT (2005) Shear strength of cohesionless soils at low stress. Geotechnique 55(6):467-478. https://doi.org/10.1680/geot.2005.55.6.467

Gibo S, Egashira K, Ohtsubo M, Nakamura S (2002) Strength recovery from residual state in reactivated landslides. Geotechnique 52(9):683-686. https://doi.org/10.1680/geot.2002.52.9.683

Hirata Y, Chigira M (2019) Landslides associated with spheroidally weathered mantle of granite porphyry induced by 2011 Typhoon Talas in the Kii Peninsula. Japan. Eng Geol 260:105217. https:// doi.org/10.1016/j.enggeo.2019.105217

Hu W, Huang RQ, McSaveney M, Zhang XH, Yao L, Shimamoto T (2018) Mineral changes quantify frictional heating during a large low-friction landslide. Geology 46(3):223-226. https://doi.org/ $10.1130 / \mathrm{G} 39662.1$

Hu W, Scaringi G, Xu Q, Van Asch TWJ, Huang RQ, Han WX (2018) Suction and rate-dependent behaviour of a shear-zone soil from a landslide in a gently-inclined mudstone-sandstone sequence in the Sichuan basin, China. Eng Geol 237:1-11. https://doi.org/10. 1016/j.enggeo.2018.02.005

Kang X, Xu GL, Yu Z, Wang S, Wang MT (2020) Experimental investigation of the interaction between water and shear-zone materials of a bedding landslide in the Three Gorges Reservoir Area, China. Bull Eng Geol Environ 79:4079-4092. https://doi.org/10. 1007/s10064-020-01812-z

Liu J, Xu Q, Wang S, Subramanian SS, Wang L, Qi X (2020) Formation and chemo-mechanical characteristics of weak clay interlayers between alternative mudstone and sandstone sequence of gently inclined landslides in Nanjiang. SW China. Bull Eng Geol Environ 1-15. https://doi.org/10.1007/s10064-020-01859-y

Lunne T, Berre T, Andersen KH, Strandvik S, Sjursen M (2006) Effects of sample disturbance and consolidation procedures on measured shear strength of soft marine Norwegian clays. Can Geotech J 43(7):726-750. https://doi.org/10.1139/t06-040

Madritsch H, Millen BMJ (2007) Hydrogeologic evidence for a continuous basal shear zone within a deep-seated gravitational slope deformation (Eastern Alps, Tyrol, Austria). Landslides 4(2):149162. https://doi.org/10.1007/s10346-006-0072-x

Maio D, Vassallo CR, Vallario M (2013) Plastic and viscous shear displacements of a deep and very slow landslide in stiff clay 
formation. Eng Geol 162:53-66. https://doi.org/10.1016/j.enggeo. 2013.05.003

Petley DN, Allison RJ (1997) The mechanics of deep-seated landslides. Earth Surf Process Landf: The Journal of the British Geomorphological Group 22(8):747-758

Prokesova R, Medvedova A, Taborik P, Snopkova Z (2012) Towards hydrological triggering mechanisms of large deep-seated landslides. Landslides 10(3):239-254. https://doi.org/10.1007/ s10346-012-0330-Z

Ronchetti F, Borgatti L, Cervi F, Corsini A (2010) Hydro-mechanical features of landslide reactivation in weak clayey rock masses. Bull Eng Geol Environ 69(2):267-274. https://doi.org/10.1007/ s10064-009-0249-3

Rosone M, Ziccarelli M, Ferrari A, Farulla CA (2018) On the reactivation of a large landslide induced by rainfall in highly fissured clays. Eng Geol 235:20-38. https://doi.org/10.1016/j.enggeo.2018. 01.016

Scaringi G (2016) Influence of pore fluid composition on clay behaviour and chemo-mechanical study of a clayey landslide. University of, Potenza, Italy (( $\mathrm{PhD}$ thesis))

Scaringi G, Di Maio C (2016) Influence of displacement rate on residual shear strength of clays. Procedia Earth Planet Sci 16:139-145. https://doi.org/10.1016/j.proeps.2016.10.015

Scaringi G, Fan XM, Xu Q, Liu C, O CJ, Domenech G, Yang F, Dai LX (2018) Some considerations on the use of numerical methods to simulate past landslides and possible new failures: the case of the recent Xinmo landslide (Sichuan, China) Landslides 15(7):1359 1375 https://doi.org/10.1007/s10346-018-0953-9

Scaringi G, Hu W, Xu Q, Huang RQ (2018) Shear-rate-dependent behavior of clayey bimaterial interfaces at landslide stress levels. Geophys Res Lett 45(2):766-777. https://doi.org/10.1002/2017G L076214

Schofield AN (2006) Interlocking, and peak and design strengths. Geotechnique 56(5):357-358. https://doi.org/10.1680/geot.2006. 56.5.357

Springman SM, Jommi C, Teysseire P (2003) Instabilities on moraine slopes induced by loss of suction: a case history. Geotechnique 53(1):3-10. https://doi.org/10.1680/geot.2003.53.1.3

Skempton AW (1985) Residual strength of clays in landslides, folded strata and the laboratory. Geotechnique 35(1):3-18. https://doi. org/10.1680/geot.1985.35.1.3

Stark TD, Choi H, McCone S (2005) Drained shear strength parameters for analysis of landslides. J Geotech Geoenviron Eng 131(5):575588. https://doi.org/10.1061/(ASCE)1090-0241(2005)131:5(575)

Stark TD, Hussain M (2010) Shear strength in preexisting landslides. J Geotech Geoenviron Eng 136(7):957-962. https://doi.org/10.1061/ (ASCE)GT.1943-5606.0000308
Tsou CY, Feng ZY, Chigira M (2011) Catastrophic landslide induced by typhoon Morakot, Shiaolin. Taiwan. Geomorphology 127(34):166-178. https://doi.org/10.1016/j.geomorph.2010.12.013

Varnes DJ (1978) Slope movement types and processes. In: Schuster RL, Krizek RJ (eds) Landslides, analysis and control, special report 176: Transportation research board. National Academy of Sciences, Washington DC, pp 11-33

Wang GH, Sassa K (2003) Pore-pressure generation and movement of rainfall-induced landslides: effects of grain size and fine-particle content. Eng Geol 69(1-2):109-125. https://doi.org/10.1016/ S0013-7952(02)00268-5

Wang JE, Wang S, Su AJ, Xiang W, Xiong CR, Blum P (2021) Simulating landslide-induced tsunamis in the Yangtze River at the Three Gorges in China. Acta Geotech. https://doi.org/10.1007/ s11440-020-01131-3

Wang S, Idinger G (2021) Centrifuge modelling of rainfall-induced slope failure in variably saturated soil. Acta Geotech. https://doi.org/10. 1007/s11440-021-01186-w

Wang S, Idinger G, Wu W (2021) Centrifuge modelling of rainfallinduced slope failure in variably saturated soil. Acta Geotech. https://doi.org/10.1007/s11440-021-01169-x

Wang S, Wang JE, Wu W, Cui DS, Su AJ, Xiang W (2020) Creep properties of clastic soil in a reactivated slow-moving landslide in the Three Gorges Reservoir Region. China. Eng Geol 267:105493. https://doi.org/10.1016/j.enggeo.2020.105493

Wang S, Wu W, Cui DS (2021) On mechanical behaviour of clastic soils: numerical simulations and constitutive modelling. Geotechnique. https://doi.org/10.1680/jgeot.20.P.184

Wang S, Wu W, Wang JE, Yin ZY, Cui DS, Xiang W (2018) Residual-state creep of clastic soil in a reactivated slow-moving landslide in the Three Gorges Reservoir Region. China. Landslides 15(12):2413-2422. https://doi.org/10.1007/s10346-018-1043-8

Xu Q, Li WH, Liu HX, Tang R, Chen SJ, Sun X (2015) Hysteresis effect on the deep-seated landslide by rainfall: The case of the Kualiangzi landslide, China. In Engineering Geology for Society and Territory - Volume 2, Springer, Cham pages 1557-1562. https://doi.org/10.1007/978-3-319-09057-3-276

Zangerl C, Eberhardt E, Perzlmaier S (2010) Kinematic behaviour and velocity characteristics of a complex deep-seated crystalline rockslide system in relation to its interaction with a dam reservoir. Eng Geol 112(1-4):53-67. https://doi.org/10.1016/j.enggeo.2010.01.001

Zezere JL, Trigo RM, Trigo IF (2005) Shallow and deep landslides induced by rainfall in the Lisbon region (Portugal): assessment of relationships with the North Atlantic Oscillation. Nat Hazards Earth Syst Sci 5:331-344. https://doi.org/10.5194/ nhess-5-331-2005 